\title{
TURKISH TRANSLATION COMPANIES' USE OF COMPUTER ASSISTED TRANSLATION TOOLS
}

Halil İbrahim Balkul ${ }^{1}$, Hüseyin Ersoy ${ }^{2}$

Abstract: Nowadays, Computer Assisted Translation (CAT) tools are undoubtedly among indispensable parts of both translation industry and academic translation world. Thanks to the variety of translation memories, machine translation systems, desktop publishing tools, and terminology management applications, the body of translations carried out in a specific time has increased in a considerable amount compared to the situation in past. In this regard, the current inquiry aims at investigating Turkish translation companies' use of CAT tools via examining the websites of 39 translation companies, which are the members of two important national translation providers' associations in Turkey.

The results of the existing research are limited to the available information presented in the websites of the aforementioned translation companies about the use of CAT tools. Further studies can shed some light on the issue in a more overarching way if the number of translation companies to be examined is increased and questionnaires are delivered more accessibly, either by paper or online. Besides, this study is an attempt to emphasize that translation companies will have much more work demand from customers if they display information technologies they master on their websites.

UDC Classification: 81, DOI: http://dx.doi.org/10.12955/cbup.v2.482

Keywords: computer assisted translation, translation market analysis, translation company, internet marketing

\section{Introduction}

The use of information technologies in translation dates back to the 1950s with the invention of direct machine translation systems (Hutchins, 1995). With great expectations from computers, it was thought that machines could translate like human translators and even computers could replace human translators entirely. However, the declaration of ALPAC report showed that automatic machine translation systems cannot operate without human translator's support in order to produce acceptable translations. There have been numerous changes in translation sector since ALPAC report was declared. Example-based machine translation systems and statistical machine translation systems arose as a result of the changes in regard to translation, much more than linguistic transfer, as cognitive and communicative activity mostly requires post-editing by a human translator. Today, there is a great deal of computer assisted translation tools (CATs) and software that can help translators produce large sums of translation briefs in a limited time. Translation memories (TMs), terminology management systems (TMSs), electronic dictionaries, online data banks, desktop publishing tools (DPTs), and localization tools (LTs) can be listed under this category (Bowker, 2002).

It needs to be accepted that machines cannot replace human translators; nevertheless, it is an undeniable fact that translators who don't use CATs will be replaced by those who do. In the $21^{\text {st }}$ century, translators are expected to produce their translation missions in different file formats. According to Translation Memories Survey 2006, only 19\% of the translators prepared their translation briefs in hardcopy documents (Lagoudaki, 2006). This percentage will most probably decrease as translation briefs are handed to translators in electronic format. Therefore, both freelance translators and translation companies need to be fully equipped for translations those are delivered in computerized formats.

Nowadays, the internet is undoubtedly an innovative instrument for shaping online business and it offers several advantages for the companies that are willing to do business with people or other companies located abroad. The internet presents some features such as constant availability of

\footnotetext{
${ }^{1}$ Halil İbrahim Balkul, Sakarya University, Sakarya, Turkey, hbalkul@sakarya.edu.tr

${ }^{2}$ Hüseyin Ersoy, Sakarya University, Sakarya, Turkey, hersoy@sakarya.edu.tr
} 
information, interactivity, efficient transfer of information, individuality, and integration of communication, as well as transaction for both companies and their potential clients (Bauer, Grether, \& Leach, 2002). There is no doubt that translation companies' websites are their gateway to the world. Due to the demand for translation services across the globe, translation companies have multiplied in any region of the world. Owing to the fact that translation market is competitive, translation service providers need to advertise themselves via different mass-media vehicles, one of which is surely the internet.

Websites are invaluable aids for translation companies to let their voices be heard in the translation sector. Since the innovations in translation sector are more needs-driven rather than research-driven, the people who need translation are much more aware of translation technologies and their importance in translation briefs (Kingscott, 1996). For this reason, it would be wise for translation companies to display CAT technologies they master on their websites in order to increase the exposure of their companies' translation products and services, and capture the attention of their potential customers.

In a survey conducted by a group of German researchers on the behavior of web users, they found out that most webpages were viewed for ten seconds or less (Weinreich, Obendorf, Herder, \& Mayer, 2008). In his article, Michael Cronin mentioned about another study conducted by an Israeli company, Clicktale. The research displayed that most of the web users from different parts of the world spend between 19 to 27 seconds before switching to a new website (Cronin, 2010). It can be deduced from the results of the aforementioned surveys that translation companies must have well-designed websites in order to stand out among other translation companies in a virtual translation market. In other words, translation companies are required to design their websites in an attention-catching format while still able to present their CAT tools they master inside. As the consciousness about CAT tools usage in translation projects increases among people who need translation, the importance of translation companies' websites will surely increase.

In CAT literature, several studies, including the works of Williams (2003), Garcia (2009b), Ersoy \& Balkul (2012), Doherty \& Moorkens (2013), Daelemans \& Hoste (2010), Alcina (2008), Bogucki (2010), Pym (2011a), and Christensen (2011), aimed to tackle different aspects of computer assisted translation, such as computer assisted translation teaching, the design and development of translation technologies, the evaluation of CAT tools, the effects of CAT tools on cognitive processes of translators, etc. However, there is a research gap in examining the websites of translation companies in terms of their CAT use in translation projects. The present study aims at filling this gap. There are three main research questions to answer in this modest study. These questions can be stated as follows:

1. Do the websites of the present translation companies give information about the translation technologies they use during translation projects?

2. Do the websites of the existing translation companies indicate the name of specific CAT tools they master? Which CAT tools are the most widely used ones in Turkish translation market?

3. Can we find any information related to the technology mastery of candidate translators needed by these translation companies in their websites?

Following this first part of the study, the next section focuses on methodology presenting the method of this research and gives information about the sample translation companies. The following chapter deals with the analyses and propounds statistical values about the research. Finally, the last section sums up the existing inquiry and puts forth some suggestions for translation companies and further researches to be carried out in this field. 


\section{Methodology}

In this study, 39 Turkish translation companies' websites were examined in order to determine whether the information about their translation technologies, utilized during their translation projects, is provided or not. The reason to choose these translation companies as our sample is the fact that these companies are the members of two important national translation providers' associations, which are Tüm Çeviri İşletmeleri Derneği (TÇiD) and Çeviri İşletmeleri Derneği (ÇID). While TÇiD is a member of European Union Associations of Translation Companies and Turkish Language Institute, ÇİD is a member of Kalite Derneği. There are 30 translation companies, which are members of ÇiD (ÇID, 2013). There are 10 translation companies enrolled in TÇİ (TÇiD, 2013). These translation companies display characteristics of Turkish translation companies, thus make them great subjects for the existing research.

Outside of translation studies field, several researches, including Huizingh (2000), Bauer \& Scharl (2000), and Ho (1997), have aimed to evaluate the effectiveness of commercial websites from different points of view. According to Miranda Gonzalez \& Palacios (2004), there must be four criteria to assess the quality of commercial websites, which are accessibility, speed, navigability and content. In our research, we adapted this model, while examining the websites of the aforementioned translation companies by just taking the fourth criteria, content, into consideration.

In the analysis process, the researchers examined each website carefully in the light of the research questions presented above. In order to be objective toward each translation company, each website was examined step by step by focusing on the every link provided by the websites. All the translation companies have active websites except from one company. Nearly all the websites are bilingual, which means that everyone who understands English and Turkish can navigate the websites to search for information they need.

\section{Results and Discussion}

The results of the current research are presented step by step under the framework of research questions in this part of the study. The names of the translation companies are kept secret in order not to affect their reputation in the sector and display the results from an objective point of view. The results obtained from the analysis carried out for the first research question, which seeks an answer for whether the translation companies' websites reveal specific information regarding their CAT tools used in their translation projects.

According to the information obtained from the analysis, it can be determined that $46 \%$ of the translation companies (18 of 39) in this survey provided details about their CAT use on their websites; on the other hand, 54\% of the translation companies (21 of 39) did not present any piece of information related to CAT use on their websites. Empirical data clearly propounds that nearly half of the Turkish translation companies did not give information about translation technologies they master on their websites even though most of them define themselves as international translation companies with their primary goals of keeping up with state-of-the art technology in the translation industry.

To repeat a crucial factor for the reliability of our analysis, it needs to be accepted that our research data are limited to the information presented in translation companies' websites, which means that some of the translation companies may utilize CAT tools in their translation projects in actuality, but fail to provide relevant information on their websites. However, it should be noted that the situation above is undoubtedly a loss of prestige for the translation companies whose aim is to open the world through internet and do business with people or companies that are most probably willing to learn the CAT tools they use. 
The second step in our research was to find answers for the second research question, which deals with the names of specific CAT tools used by Turkish translation companies. 21 of 39 translation companies did not provide information about their CAT use on their websites; therefore, the answers of the second research questions were determined by examining the remaining 18 translation companies' websites, which indicated their use of CAT tools for translation projects. Table 1 summarizes the analysis carried out to answer the second research question.

\begin{tabular}{|c|c|}
\hline Translation Company & CAT Tools \\
\hline Company 3 & Trados, Dejavu, Omega T \\
\hline Company 7 & $\begin{array}{l}\text { SDL Trados, Star Transit, RC Wintrans, Metatexis, Microsoft } \\
\text { Helium, Microsoft Localization Studio }\end{array}$ \\
\hline Company 12 & $\begin{array}{l}\text { Adobe FrameMaker, Adobe Illustrator, Adobe Freehand, } \\
\text { Adobe InDesign, Adobe Photoshop, Macromedia, } \\
\text { Dreamweaver, Macromedia Fireworks, Macromedia Flash, } \\
\text { Microsoft Office suite, Quark Xpress, SDLX-Trados, Alchemy } \\
\text { Catalyst, Star Transit XV }\end{array}$ \\
\hline Company 13 & Adobe Acrobat, FrameMaker, FreeHand \\
\hline Company 14 & $\begin{array}{l}\text { Trados } 2007 \text { Professional, SDLX 2007, QuarkXPress, Adobe } \\
\text { InDesign, Scribus, Microsoft Publisher ve Apple Pages }\end{array}$ \\
\hline Company 15, 16 & No specific CAT tools name specified \\
\hline Company 17 & Catalyst, Wordfast, SDL Trados Studio, Adobe Creative Suite \\
\hline Company 18 & SDL Trados \\
\hline Company 22 & $\begin{array}{l}\text { Trados - Tag Editor, SDLX, Helium, WordFast, Transit, Red, } \\
\text { IBM Translation Manager, HyperHub, Passalo, Translation } \\
\text { Workspace, MemoQ, T-Stream, Idiom Workbench, Fortis, } \\
\text { Dejavu, LocStudio }\end{array}$ \\
\hline Company 24 & Trados \\
\hline Company 25 & $\begin{array}{l}\text { Trados } 7.5 \text { Translators Edition, Trados 7.5 Freelance Edition, } \\
\text { Fine Reader, Acrobat Adobe exchange CE }\end{array}$ \\
\hline Company 26 & $\begin{array}{l}\text { Across, SDL Trados, OCP, Adobe Photoshop, Adobe } \\
\text { InDesign, Adobe FrameMaker, QuarkXPress, Adobe } \\
\text { illustrator }\end{array}$ \\
\hline Company 27 & Quark, Adobe Photoshop, Corel, and Trados. \\
\hline Company 28 & Trados \\
\hline Company 29 & $\begin{array}{l}\text { Trados, SDLX, MemoQ, Star Transit, DejaVu, Translation } \\
\text { Workspace, Wordfast, Lokalize, GlobalSight, OmegaT, } \\
\text { POedit, Pootle, Wordbee,Catalyst, Passolo, SDL } \\
\text { Insight,Illustrator,AdobePageMaker, QuarkXpress, } \\
\text { Freehand,Corel Draw, Adobe Frame Maker }\end{array}$ \\
\hline Company 30 & MemoQ \\
\hline Company 36 & SDL Trados, Trados Power LSP \\
\hline
\end{tabular}

According to the information provided by Table 1, it is possible to reach some conclusions about CAT tools usage among Turkish translation companies. As clearly seen, the companies make use of various translation memory systems, desktop publishing tools, and localization tools. SDL Trados seems to be the most widely preferred translation memory system (78\%) among Turkish translation companies. 
This result is similar to the results obtained by Canım (2008) and Atila (2013), in which SDL Trados was found to be the leading translation memory software in Turkish translation market. Another finding is that two of the translation companies above did not definitely indicate the names of translation technologies used on their websites. From our point of view, this revelation proves to be a disadvantage for them in order to compete against those who are willing to work with specific translation technologies. This is because selected CAT tools are more suitable for certain translation briefs with the desired file formats.

Furthermore, 9 of 18 translation companies (50\%) used Adobe programs in desktop publishing. To present details about localization tools used by translation companies in Turkey, it can be stated that 5 of 18 translation companies have indicated the names of localization tools they used on their websites; Alchemy Catalyst is the most-widely used localization tool by Turkish translation companies (among 3 of 5 translation companies, which specifically displayed the names of localization tools they master).

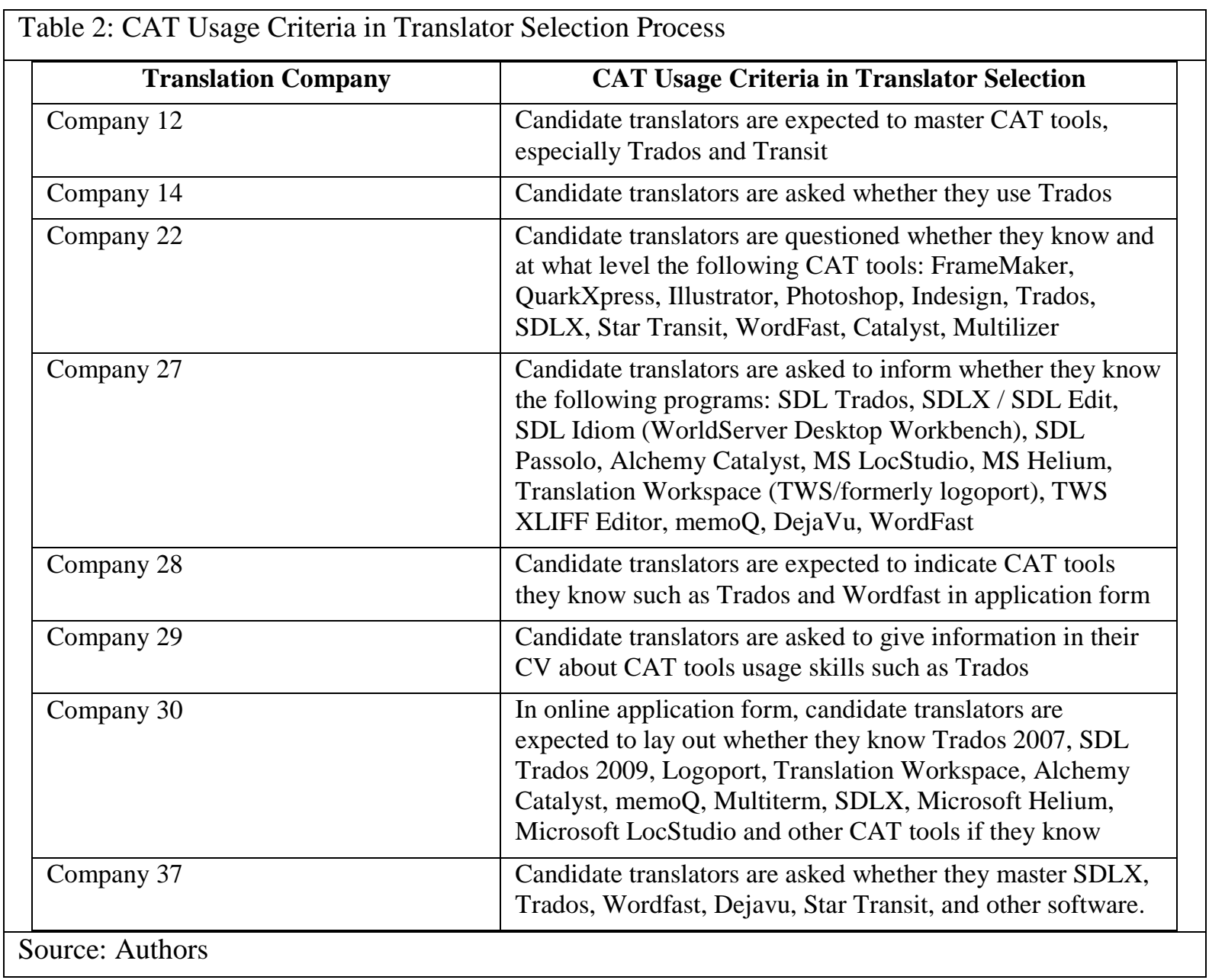

The last step in the current research is to find the answer for the third research question, which explores whether there is any information related to the technology mastery of the translation candidates, needed by the translation companies, on their websites. More than half of the translation companies (24 of 39) did not specify any CAT usage criteria in translator selection on their websites even though nearly all the translation companies in this research have a human resources segment, on their websites, to communicate with their translation candidates. However, most of the human resources sections of the mentioned websites were found to be inefficient and plain. They can be considered as just a contact section for translation candidates, rather than a space for providing detailed information about the skills and experiences required working for that company as a translator. On the other hand, 15 of 39 translation companies have highlighted CAT usage criteria on 
the translator's application form in the hiring section on their websites. Seven of these 15 companies just question whether the candidate translators know how to use CAT tools or if CAT tools knowledge is regarded as an advantage to be considered for translator position in the hiring section on the aforementioned translation companies' websites. Table 2 describes companies those require specific CAT tools knowledge from candidate translators.

According to Table 2, some translation companies explicitly question candidate translators whether they are competent with some specific translation technologies. Aside from the findings summarized in Table 1, 8 of 15 translation companies desire to learn whether their translation candidates have mastered Trados translation memory system. Except for the mastery of translation memory systems, some companies only desire to determine whether their translation candidates can use desktop publishing tools and localization tools.

To comment on Table 2 from a different perspective, it can also be put forward that some translation companies demand CAT knowledge from translation candidates even though they have not mentioned any information related to CAT use in translation projects on their websites. As noted at the beginning of the article, the contradiction reported above might have originated from the fact that these translation companies may have failed to emphasize their requirement regarding CAT tools usage on their websites, but in actuality they require such usage of the translation technologies in their translation tasks.

On the contrary, it can also be determined from Table 2 that some translation companies do not question their translation candidates about CAT usage knowledge, but provide relevant requirement in human resources section on their websites. Companies 3, 7, 13, 16, 17, 18, 24, 26, and 36 are good examples for the aforementioned situation. The reason behind this situation might be two-fold. One reason could be that these translation companies might have forgotten to add CAT tools usage criteria for their translation candidates on their websites. Another possibility could be that the aforementioned translation companies may have failed to update their web contents to be consistent with their CAT tools usage in the translation projects.

\section{Conclusion}

This research aims at investigating CAT tools usage among Turkish translation companies by examining the websites of 39 Turkish-based translation companies, which are enrolled in two highly distinguished Turkish translation companies' associations. The research was carried out under the framework of three research questions that were designed to explore the following issues: (1) CAT usage of Turkish translation companies, (2) the names of specific CAT tools used by Turkish translation companies, and (3) Turkish translation companies' CAT usage competency demand from their translation candidates.

Throughout the research, it was found out that less than half of the companies (46\%) provides information regarding CAT tools usage on their websites being utilized in translation projects; however, it needs to be stressed that the current result is only limited to the information obtained from the websites of the translation companies under consideration. These companies might use CAT tools in actuality, but they may have failed to mention about CAT usage on their websites. From the perspective of this research, these companies need to be more attentive with their web contents and design because their websites are their windows to endless opportunities in the translation industry, which is growing rapidly and becoming more competitive. They need to provide every bit of necessary detail on their websites in order to capture the attention of their potential customers.

Another important concluding remark to focus on is that Trados was found to be the leading commercial translation memory software in Turkish translation sector; the current result coincides 
with several translation market analysis carried out both in Turkey and abroad (see: Canım, 2008 and Lagoudaki, 2006). In addition, Turkish translation companies were found to make use of localization tools and desktop publishing tools in their translation projects. While Alchemy Catalyst is the mostwidely used localization tool by Turkish translation companies, Adobe Programs were found to be the most popular ones among desktop publishing tools.

To our great surprise, some translation companies were observed not to have indicated the names of translation technologies which they applied in their translation briefs, despite the fact that they had noted the usage of CAT tools on their websites. This situation may draw some negative views for them since some translation service seekers expect translators to be able to use some specific programs; therefore, it may be undesirable to seek services from this type of translation companies. Moreover, the possibility of translation service seekers coming across the website of a specific translation company on an internet search depends on the keywords they enter. In such kind of a situation, the chance of the website of a translation company's being discovered by a translation service seeker depends how easily discovered are the keywords and specific names of translation technologies they present on their websites.

In the last research question, it was examined whether our sample translation companies specify their demand for CAT tools usage competency from translation candidates in human resources section on their websites. The findings revealed that some translation companies want their prospective translators to be able to use CAT tools whether they are specified on their websites or not. On the contrary, some translation companies have not questioned CAT usage knowledge, while there is evidence of the requirement specified on their websites. Besides, Trados was found to be the most popular translation memory system, which was expected to be mastered by translation candidates from our sample translation companies.

To point out another significant detail, it is a well-known fact that translation technologies are important in several fields of translation world such as academia, translation-related research, and translation sector. In this study, we emphasized the importance of CAT tools usage from the perspective of translation companies by examining their websites. Keeping the significance of translation technologies in mind, it would be reasonable to note that translation schools need to train future translators to be fully competent with the-state-of-the-art technology.

Overall, it is crucial to note that further detailed researches can shed light on CAT tools usage of translation companies either by examining their websites or using different data collection methods. Sampling body can be enlarged and research questions dealing with different perspectives of translation companies' CAT tools use can be designed to conduct future inquiries in the related literature. Last but not least, translation companies from different countries can be compared and contrasted in terms of relevant information detailing their CAT tools usage on their websites.

\section{References}

Alcina, A. (2008). Translation technologies: Scope, tools and resources. Target. International Journal of Translation Studies, 20(1), 79-102. doi:10.1075/target.20.1.05alc

Atila, O. (2013). A Model for Technical Translation Training in University Departments of Translation \& Interpretation in Line with Translation Market Requirements in Turkey. Unpublished Master's Thesis. Atılım University, Ankara, Turkey.

Bauer, C., \& Scharl, A. (2000). Quantitative Evaluation of Web Site Content and Structure. Internet Research: Electronic Networking Applications and Policy, 10(1), 31-43, doi:10.1108/10662240010312138

Bauer, H. H., Grether, M., \& Leach, M. (2002). Building Customer Relations over the Internet. Industrial Marketing Management, 31(2), 155-163. doi:10.1016/S0019-8501(01)00186-9

Bogucki, Ł. (Ed.). (2010). Teaching Translation and Interpreting: Challenges and Practices. Cambridge Scholars. 
Bowker, L. (2002). Computer-Assisted Translation Technology: A Practical Introduction. Ottawa: University of Ottawa Press.

Canım, S. (2008).Türkiye’de ÇeviriBürolarında Web SitesiYerelleştirmeleri ve Bu Süreçte Bilgi Teknolojilerinin Kullanımı [The process of web site localization in translation bureaus in turkey and the use of information technologies]. Unpublished Master's Thesis, Istanbul University, Istanbul, Turkey.

Christensen, T. P. (2011). Studies on the Mental Processes in Translation Memory-Assisted Translation-the State of the Art. Trans-kom. ZeitschriftfürTranslationswissenschaft und Fachkommunikation, 4(2), 137-160.

Cronin, M. (2010). The Translation Crowd. Revistatradumàtica, 8. Retrieved from http://www.fti.uab.cat/tradumatica/revista/ num8/articles/04/04.pdf

Çi̇D (2013). Çeviri Işsletmeleri Derneği Üyeleri. Retrieved May 4, 2013 from http://www.cid.org.tr/uyeler.asp

Daelemans, W., \& Hoste, V. (2010). Evaluation of translation technology. Linguistica Antverpiensia New Series, 8(1): 9-13.

Doherty, S., \& Moorkens, J. (2013). Investigating the Experience of Translation Technology Labs: Pedagogical Implications. The Journal of Specialised Translation, 19(1), 122-136.

Ersoy, H., \& Balkul, H. İ. (2012). Teknolojik Gelişmelerin Çevirmen ve Çeviri Mesleği Açısından Olumlu ve Olumsuz Etkileri: Çeviri AlanındaYeniYaklaşımlar [The Positive and Negative Effects of Technological Developments From The Perspective of Translator and Translation Profession: New Approaches in Translation Field]. Journal of Academic Inquiries, $7(2), 309-322$.

Garcia, I. (2009b). Research on Translation Tools. In A. Pym, \& A. Perekrestenko (Eds.), Translation Research Projects (pp. 34-41), 2.

Ho, J. (1997). Evaluating the World Wide Web: A global study of commercial sites. Journal of Computer Mediated Communication, 3(1).

Huizingh, E. (2000). The Content and Design of Web Sites: An Empirical Study. Information \& Management, 37,123-134. doi:10.1016/S0378-7206(99)00044-0

Hutchins, W. J. (1995). Machine Translation: A Brief History. In E. F. K. Koerner, \& R. E. Asher (Eds.), Concise History of the Language Sciences: From the Sumerians to the Cognitivists (pp. 431-445). Oxford: Pergamon Press.

Weinreich, H., Obendorf, H., Herder, E., \& Mayer, M. (2008). Not Quite the Average: An Empirical Study of Web Use. ACM Trans. Web, 2(1), 1-31. doi:10.1145/1326561.1326566

Kingscott, G. (1996). The Impact of Technology and the Implications for Teaching. In C. Dollerup, \& V. Appel (Eds.), Teaching Translation and Interpreting 3: New Horizons (pp. 295-300). Amsterdam and Philadelphia: John Benjamins.

Lagoudaki, E. (2006). Translation memories survey 2006: Users' perceptions around TM use. Proceedings of the ASLIB International Conference Translating \& the Computer, 28(1), 1-29.

Miranda González, F. J., \& Palacios, B. (2004). Quantitative Evaluation of Commercial Web Sites: An Empirical Study of Spanish Firms. International Journal of Information Management, 24(4), 313-328. doi: 10.1016/j.ijinfomgt.2004.04.009

Pym, Anthony. (2011a.) What Technology does to Translating. The International Journal for Translation and Interpreting Research, 3(1), 1-9.

TÇİD. (2013). Our Members. Retrieved May 8, 2013 from http://www.tcid.org.tr/en/our-members/index.php

Williams, D. A. (2003). Absorbing Technology: Translation Pedagogy and Networked-Communication Culture. Meta: Journal des traducteurs, 48(3), 361-369. doi:10.7202/007596ar 